\title{
Opioid-induced respiratory depression: reversal by non-opioid drugs
}

\author{
Rutger van der Schier, Margot Roozekrans, Monique van Velzen, \\ Albert Dahan* and Marieke Niesters
}

Address: Department of Anesthesiology, Anesthesia \& Pain Research Unit, Leiden University Medical Center, Building 1, Postzone P05-Q, P.O. Box 9600, 2300 RC Leiden, The Netherlands

* Corresponding author: Albert Dahan (a.dahan@lumc.nl)

Fl000Prime Reports 2014, 6:79 (doi:10.12703/P6-79)

All FI000Prime Reports articles are distributed under the terms of the Creative Commons Attribution-Non Commercial License (http://creativecommons.org/licenses/by-nc/3.0/legalcode), which permits non-commercial use, distribution, and reproduction in any medium, provided the original work is properly cited.

The electronic version of this article is the complete one and can be found at: http://f1000.com/prime/reports/m/6/79

\begin{abstract}
The human body is critically dependent on the ventilatory control system for adequate uptake of oxygen and removal of carbon dioxide $\left(\mathrm{CO}_{2}\right)$. Potent opioid analgesics, through their actions on $\mu$-opioid receptor (MOR) expressed on respiratory neurons in the brainstem, depress ventilation. Opioid-induced respiratory depression (OIRD) is potentially life threatening and the cause of substantial morbidity and mortality. One possible way of prevention of OIRD is by adding a respiratory stimulant to the opioid treatment, which through activation of non-opioidergic pathways will excite breathing and consequently will offset OIRD and should not affect analgesia. Various new respiratory stimulants are currently under investigation including (a) potassium channel blockers acting at the carotid bodies, and (b) ampakines and (c) serotonin receptor agonists acting within the brainstem. (a) GAL-02I targets $\mathrm{BK}_{\mathrm{Ca}^{-} \text {-channels. Initial }}$ animal and human experimental evidence indicates that this potassium channel blocker is a potent respiratory stimulant that reverses OIRD without affecting antinociception. GALO2I is safe and better tolerated than the older $\mathrm{K}^{+}$-channel blocker doxapram and more efficacious in its effect on respiration. (b) Ampakines modulate glutamatergic respiratory neurons in brainstem respiratory centers. Various ampakines have been studied showing their ability to increase respiratory drive during OIRD by increasing respiratory rate. Currently, CX7I7 is the most promising ampakine for use in humans as it is safe and does not affect opioid analgesia. (c) While animal studies show that serotonin receptor agonists increase respiratory drive via activation of serotonin receptors in brainstem respiratory centers, human studies are without success. Further clinical studies are required to improve our care of patients that are treated with potent opioid analgesics. The use of non-opioid adjuvants may reduce the probability of OIRD but does never relieve us of our duty to continuously monitor these patients, irrespective whether they are treated in-house or in an ambulatory setting.
\end{abstract}

\section{The ventilatory control system and opioid-induced respiratory depression}

Humans are critically dependent on the cardiorespiratory control system for adequate uptake of oxygen and removal of $\mathrm{CO}_{2}$ via the lungs [1]. Ventilation is controlled by two systems: the chemical or metabolic control of breathing and the behavioral control system. The behavioral control system is active during wakefulness and rapid-eye-movement sleep and allows the adjustment of breathing to specific circumstances and needs such as speaking, eating, reading, surprise, anxiety, and pain. Several brain areas, including the cortex, limbic system, and hypothalamus, are involved in the behavioral control system. The chemical control system is dependent on the chemical composition of arterial blood and cerebrospinal fluid - most importantly, $\mathrm{pH}, \mathrm{CO}_{2}$ partial pressure $\left(\mathrm{pCO}_{2}\right)$, and oxygen partial pressure $\left(\mathrm{pO}_{2}\right)$ - and relies on a set of chemosensors in the brainstem (central chemoreceptors) and in the carotid bodies (peripheral chemoreceptors) [2]. Deviations from 
chemical cellular homeostasis will result in compensatory mechanisms, primarily by adaptations in breathing frequency and tidal volume. For example, acidosis and hypoxia will activate specific chemosensitive cells in the chemoreceptors, causing a hyperventilatory response aimed at restoration of $\mathrm{pO}_{2}$ and $\mathrm{pCO}_{2}$ toward normoxic (arterial $\mathrm{pO}_{2}$ of 95 to $110 \mathrm{~mm} \mathrm{Hg}$ ) and normocapnic (38 to $42 \mathrm{~mm} \mathrm{Hg}$ ) values, respectively. The two control systems interact in a complex fashion and come together in multiple respiratory centers in the brainstem, where the drive to breathe is generated (Figure 1). A variety of different receptors are expressed on respiratory neurons,

Figure I. Simple schematic representation of the ventilatory control system

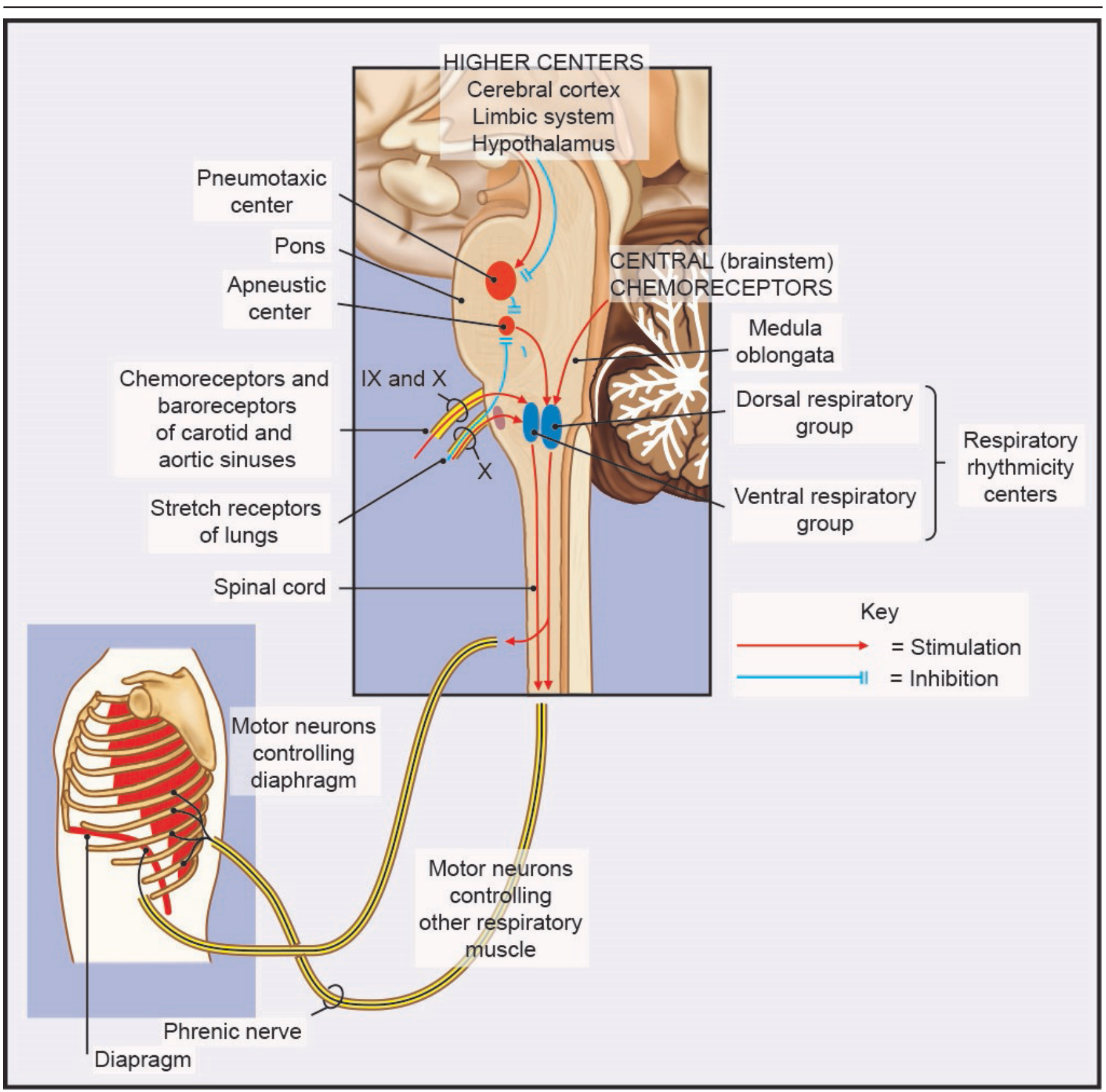

Information from peripheral and central chemoreceptors, the lungs and higher brain centers is integrated in brainstem respiratory centers, which through efferent pathways control motor neurons of the diaphragm and other respiratory muscles so that breathing is adapted to both metabolic and behavioral needs. 
and their activation or inhibition will directly affect breathing [1]. Depending on the circumstances, this may be advantageous (specific receptor agonists/antagonists may beneficially influence our breathing) or disadvantageous (specific drugs may depress ventilation, causing potentially fatal conditions).

In current medical practice, the most important group of drugs that depress ventilation are opioids, which include both the natural derivatives from the poppy plant, Papaver somniferum (opiates such as morphine), and (semi) synthetic opioids (the fenylpiperidines such as fentanyl, sufentanil, alfentanil, and remifentanil and others such as buprenorphine, oxycodone, and methadone) [3]. Opioids are used to treat acute and chronic pain (inside and outside of the hospital setting) and play an important role in palliative care. In patients receiving high-dose opioids in the community for the treatment of non-malignant pain, inadvertent overdose or addiction is a major cause of morbidity and mortality [4]. Furthermore, these prescription opioids often change hands, resulting in misuse and abuse outside of the medical setting with casualties from overdose or dangerous drug combinations (for example, opioids combined with sedatives, alcohol). Currently, more individuals die from prescription opioids than from illicit drugs (for example, heroin and cocaine). In the US, the number of prescription opioid overdose deaths increased from 4,400 in 1999 (12 individuals per day) to 16,000 in 2010 (44 individuals per day) [5]. Over this same period, there were similar increases in opioid sales (more than 4 million Americans per year receive longacting or prolonged-release opioids for treatment of chronic pain) and admissions in opioid-abuse treatment centers $(>400 \%)$ [5]. The rise in opioid prescriptions in the US is partly related to the increased awareness of clinicians to diagnose and treat chronic pain, to the increase in the number of opioid formulations being marketed, and to the pressure from the industry on physicians to prescribe opioids [6]. Although we have a good idea of the number of individuals who die from prescription opioids, the number of near-fatal events remains unknown. Our educated guess is that non-fatal respiratory events from prescription opioids exceed fatal events by at least a factor of 100. In agreement with the data from the community, parenteral opioids in the clinical setting are considered a major and independent risk factor for development of cardiorespiratory arrest [7-9].

The main cause of opioid fatalities is cardiorespiratory arrest initiated by OIRD with subsequent hypoxia and hypercapnia $[1,3,7-9]$. OIRD is directly related to the activation of opioid receptors expressed on respiratory neurons in the central nervous system. Since opioid receptors are abundant in brainstem respiratory centers
[10], various opioid-related effects are observed: depression of the ventilatory responses to hypercapnia and hypoxia, depression of ventilation (related to reductions in respiratory rate and volume) and the wakefulness drive to breathe, irregular breathing, suppression of pharyngeal muscle (including the tongue) function, and depression of the arousal response. Various patterns of OIRD may be observed, depending on multiple factors, including the physicochemical properties of the opioid (responsible for the drug's kinetics and dynamics), opioid dose, route of administration, speed at which the opioid concentration rises at its site of action (for example, a slow rise enables the patient to accumulate $\mathrm{CO}_{2}$ which offsets OIRD [11]), underlying disease (for example, recurrent hypoxic events enhance opioid sensitivity $[12,13]$ ), inspired oxygen concentration (a high fraction of inspired oxygen $\left[\mathrm{FiO}_{2}\right]$ enhances OIRD Figure 2) [14], genetics, and gender. The clinical picture that emerges is related to complex interactions with brain sites involved in arousal, nociception, nausea/vomiting, and so on. Some patterns of OIRD are dominated by superficial ventilation, reduced respiratory rates, and eventually central apnea; others by cyclic breathing and obstructive events.

In light of the above, an import question is how to prevent OIRD. Various solutions come to mind. One possibility is to develop analgesics that rely on their analgesic effect by acting at opioidergic and non-opioidergic pathways simultaneously. One such drug is tapentadol [15], which is an MOR agonist (with a weaker affinity for the MOR than morphine) and noradrenaline re-uptake inhibitor. Tapentadol produces potent analgesia due to analgesic synergy from its two mechanisms of action. Theoretically, tapentadol would produce limited respiratory depression. However, no studies on the respiratory effects of tapentadol are currently available. Another possibility would be to add a respiratory stimulant to the opioid, which through activation of non-opioidergic pathways will excite breathing and consequently offset OIRD. It is important that these adjuvants not affect analgesia. Respiratory stimulants used in the last four or five decades include $\mathrm{CO}_{2}$, doxapram, almitrine, acetazolamide, theophylline, and caffeine. Whereas some of these are still in use today, none has been developed to treat OIRD and most come with side effects that limit their clinical use [16]. Currently, novel drugs are being developed or investigated (or both) to treat OIRD specifically [1]. These agents will be discussed below.

These non-opioid adjuvants are different from naloxone, which is an opioid receptor antagonist and restores breathing by its antagonist effect at the MOR $[1,17]$. Naloxone is used to treat OIRD; however, owing to its 
Figure 2. Opioid-induced respiratory depression following a $50 \mu \mathrm{g}$ intravenous bolus dose of remifentanil in one person during air breathing (left) and during inspiration of $50 \%$ oxygen in $\mathbf{N}_{2}$
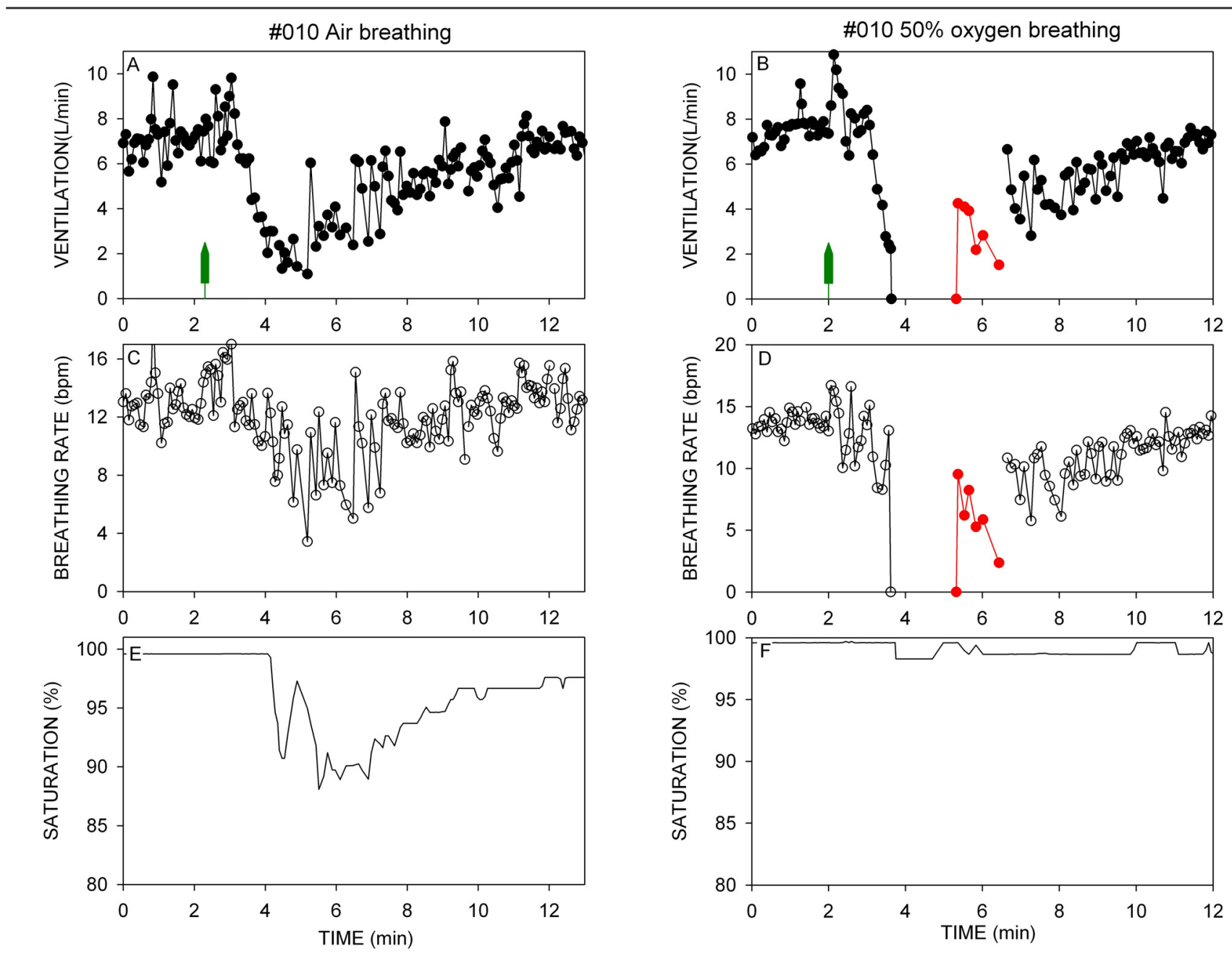

(A, B) Breath-to-breath ventilation in L/min. (C, D) Breathing frequency. (E, F) Oxygen saturation. The green syringes indicate opioid administration. The red data indicate artificial mask ventilation. Data from [II] with permission. Abbreviations: bpm, breaths per minute.

mechanistic pathways, it will reduce or abolish opioid analgesia as well. An additional drawback of naloxone is its short half-life (its elimination half-life is 15 to 20 minutes [17]). Therefore, a single naloxone bolus injection may be followed by "re-narcotization" (that is, the return of OIRD following a [short] period of adequate ventilation, potentially putting the patient's life further at risk, especially when long-acting or high-dose opioids are the cause of OIRD).

\section{Reversal of opioid-induced respiratory depression by non-opioids}

Respiratory stimulants that act through non-opioid receptor systems are of real therapeutic benefit as they may restore breathing to an acceptable level or even prevent OIRD without affecting analgesia. Three drug classes will be discussed: potassium channel blockers, ampakines, and 5-hydroxytryptamine (serotonin, 5HT) receptor agonists.

\section{Potassium channel blockers}

The oldest (available since the 1960s) and best known $\mathrm{K}^{+}$channel blocker that stimulates breathing is doxapram. Doxapram inhibits background $\mathrm{K}^{+}$channels (TASK1, TASK3, and the TASK1/3 heterodimer) on type 1 carotid body cells $[18,19]$. The channels mediate background "leak" $\mathrm{K}^{+}$current, thereby regulating neuronal excitability $[18,19]$. TASK-channel antagonism by doxapram produces 
respiratory stimulation [20]. However, doxapram comes with many side effects, including anxiety/panic attacks, sympathoexcitation, sweating, and convulsions [16]. Cardiovascular stimulation causes hypertension and increases cardiac output. This is not without consequences. For example, we recently showed that the doxapram-induced increase in cardiac output was associated with reduced plasma concentrations of the opioid alfentanil [21]. This evidently will reduce OIRD but also analgesia. In the rat, Cotten [19] investigated the effect of PK-THPP and A1899, potent potassium-channel blockers that act selectively as TASK1 and TASK3 antagonists. He showed that both agents produced greater respiratory stimulation than doxapram but with little effect on blood pressure. To the best of our knowledge, no studies have been done in humans.

GAL-021 is a novel developed $\mathrm{K}^{+}$-channel blocker, blocking $\mathrm{BK}_{\mathrm{Ca}}$ channels (large-conductance $\mathrm{Ca}^{2+} /$ voltageactivated $\mathrm{K}^{+}$channels) [22]. Initial evidence that GAL-021 is a respiratory stimulant acting predominantly at the carotid bodies and reverses OIRD without affecting antinociception comes from animal studies [16]. For example, the efficacy of GAL-021 is severely abolished in carotid body resected animals and in mice lacking essential subunits of the $\mathrm{BK}_{\mathrm{Ca}}$ channel. Phase 1 human studies show that GAL-021 is safe and indeed acts as a potent respiratory stimulant [23]. We recently assessed the effect of GAL-021 on alfentanil-induced respiratory depression (alfentanil plasma concentrations of 40 and $100 \mathrm{ng} / \mathrm{mL}$ ) in healthy volunteers and observed that GAL-021 at plasma concentrations ranging from 400 to $1200 \mathrm{ng} / \mathrm{mL}$ increases opioid-depressed ventilation (Figure 3) [24,25]. Important additional observations from our study were that GAL-021 does not reduce analgesia and that it has no effect on sedation, cardiac output, or blood pressure. Furthermore, a pharmacokineticpharmacodynamic analysis of the data revealed that GAL-021 has a rapid onset time/offset time (blood-effectsite equilibration half-life of less than 0.5 minutes), making this drug an attractive alternative to naloxone (M. Roozekrans, unpublished observation). Further studies will be needed to assess the full dose-response relationship at higher opioid and higher GAL-021 dosages and consequently more severe respiratory depression.

\section{Ampakines}

Ventilatory drive may be modulated by manipulation of glutamatergic and serotonergic neurotransmission in respiratory centers in the brainstem (Figure 1) [26]. An important respiratory area identified in animals is the pre-Bötzinger complex, which is involved in respiratory rhythm generation [27]. The pre-Bötzinger complex is
Figure 3. Effect of GAL-02 I on alfentanil-induced respiratory depression in one person

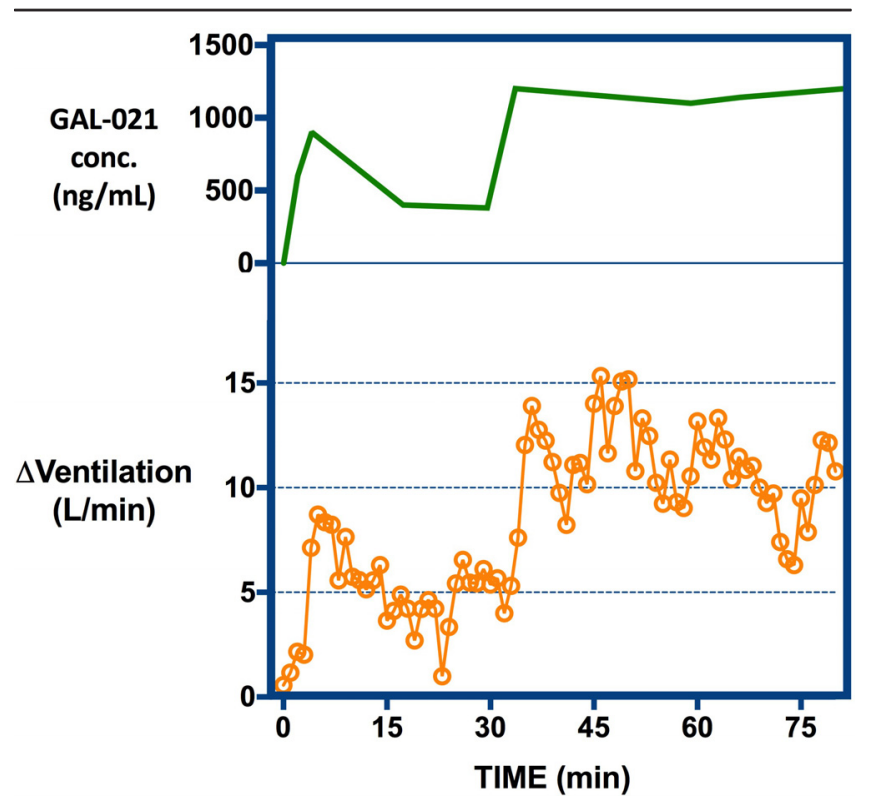

The bottom graph depicts the increase in ventilation during alfentanil infusion (plasma concentration kept constant at $50 \mu \mathrm{g} / \mathrm{mL}$ ) following low- and high-dose GAL-02I (top graph). Low-dose GAL-02I increases ventilation by about $5 \mathrm{~L} / \mathrm{min}$, high-dose by 10 to $15 \mathrm{~L} / \mathrm{min}$. Data are from refs. [21,22].

part of the ventral respiratory group or column [28]. Animal studies show that ampakines increase respiratory rate by their action at amino-3-hydroxy-5-methylD-aspartate (AMPA) receptors in the pre-Bötzinger complex. In published studies, various ampakines have shown their ability to increase respiratory drive during OIRD (by increasing respiratory rate and the slope of the ventilatory response to $\mathrm{CO}_{2}$ ) [29-31]. The most promising ampakine is CX717. It is safe for use in humans and is available for treatment of attention deficit hyperactivity disorder and Alzheimer's disease. In humans, CX717 prevents alfentanil-induced respiratory depression without affecting analgesia, although sedation tended to increase [31]. In this study, the volunteers were pre-treated with the ampakine, which allows prevention of OIRD but not treatment of established OIRD, and no opioid dose-response data were presented. Hence, further (dose-response) studies are required to give a critical appraisal of this therapy and assess whether CX717 is clinically useful in the prevention of OIRD. Possibly, these drugs may prove useful to prevent nonopioid-induced respiratory depression such as reduced ventilation from propofol [32]. To the best of our knowledge, no further human studies are currently performed with CX717 (search of ClinicalTrials.gov 
using terms "ampakine" and "respiratory depression" on 1 May 2014).

\section{Serotonin receptor agonists}

Animal studies show that serotonin agonists increase respiratory drive via actions at 5HT1A, 5HT7, and 5HT4a receptors $[1,33]$. In human volunteers, these agents were not successful. For example, the 5HT1A agonist buspirone and the 5HT4a agonist mosapride are without effect on OIRD in humans [34,35]. The lack of efficacy in humans may be related to low potency or the lower brain concentrations achieved in human studies compared with animal studies. Owing to the appearance of side effects (for example, nausea/vomiting), higher dosages are often not possible in humans.

\section{Primum non nocere (above all, do no harm)}

OIRD is a serious problem that requires our attention and a rapid solution. The use of non-opioid adjuvants such as those discussed above (for example, CX717 or GAL-021) may reduce the probability of OIRD. In a recent editorial entitled "Primum non nocere, or How to resolve drug-induced respiratory depression" [36], we discussed the various patient populations that may require treatment with these respiratory stimulants. We argued that all patients who receive opioid treatment are at potential risk for OIRD and hence all patients on opioids may be expected to belong to the target population for treatment with non-opioid respiratory stimulants, although actual treatment possibilities will depend on the available formulations. Furthermore, in three analyses of case reports on OIRD published since 1980 , it became apparent that in a large number of cases neither specific patient factors nor specific case-related factors dominate the general picture of OIRD [37-39]. This indicated that $a$ priori prediction of OIRD is difficult if not impossible. Various options may be considered to reduce the probability of OIRD, such as by (a) reducing opioid dose by adding opioid-sparing medication, (b) restricting the prescription of opioids in the ambulatory setting to well-trained specialists as may be found in specialist pain clinics, and (c) exercising caution in opioid prescription by applying strict opioid titration rules in opioid-naïve patients. Furthermore, as we previously stated [36], even with appropriate respiratory stimulants on board, the risk of OIRD does not vanish and hence we have to additionally apply optimal patient monitoring for patients who are treated in-house as well as those treated in the ambulatory setting. An example of a possibly useful monitor that is used in the clinical setting is the Integrated Pulmonary Index ${ }^{\mathrm{TM}}$ (IPI, Covidien, Mansfield, MA) that integrates four measurements (pulse rate, end-tidal $\mathrm{CO}_{2}$, oxygen saturation, and respiratory rate) by applying a fuzzy logic algorithm to come up with a real-time index ranging from 1 (the patient requires immediate attention) to 10 ("normal" condition). The IPI has been tested in postoperative adult patients and pediatric patients during deep sedation $[40,41]$. In both studies, the IPI gave an adequate indication of the respiratory status of the patient. Further studies are required to assess whether the IPI is less noise-sensitive than commonly used respiratory monitors, which are known to cause repetitive false alarms and consequently alarm fatigue [42]. For the ambulatory (community) setting, there is the need for the development of a small and inexpensive intelligent monitor that continuously and accurately senses and monitors the cardiovascular and respiratory state of the patient. Currently, such a monitor is not available.

\section{Abbreviations}

5-HT, 5-hydroxytryptamine (serotonin); $\mathrm{CO}_{2}$, carbon dioxide; IPI, Integrated Pulmonary Index ${ }^{\mathrm{TM}} ; \mathrm{MOR}, \mu$ opioid receptor; OIRD, opioid-induced respiratory depression; $\mathrm{pCO}_{2}$, carbon dioxide partial pressure; $\mathrm{pO}_{2}$, oxygen partial pressure.

\section{Disclosures}

Albert Dahan is the head of The Anesthesia \& Pain Research Unit, which has been involved in performing phase 1 and 2 studies on opioid-induced respiratory depression and its prevention. These studies were sponsored by Mundipharma Research Ltd, Galleon Pharmaceuticals Corp., and Revive Therapeutics Inc.

\section{References}

I. Dahan A, Aarts L, Smith T: Incidence, reversal and prevention of opioid-induced respiratory depression. Anesthesiology 2010, I | 2:226-38.

\section{FIOOOPrime}

2. Dahan A, Nieuwenhuijs D, Teppema L: Plasticity of central chemoreceptors: Effect of bilateral carotid body resection on central $\mathrm{CO}_{2}$ sensitivity. PLoS One 2007, 4:e239.

\section{FlOOOPrime}

RECOMMENDED

3. Dahan A, Niesters M, Olofsen E, Smith T, Overdyk F: Opioids. In Clinical Anesthesia. $7^{\text {th }}$ edition. Edited by Barash PG, Cullen BF, Stoelting RK, Cahalan MK, Stock MC, Ortega R. Philadelphia: Lippincott, Williams \& Wilkins; 20I3:50I-22.

4. Lötsch J, Dudziak R, Freyenhagen R, Marschner J, Geisslinger G: Fatal respiratory depression after multiple intravenous morphine injections. Clin Pharmacokinet 2006, 45:105I-60.

FlOOOPrime

RECOMMENDED

5. Volow ND, Frieden TR, Hyde PS, Cha SS: Medication-assisted therapies - Tackling the opioid overdose epidemic. New Eng J Med 20I4, 370:2063-6. 
6. Okie S: A flood of opioids, a rising tide of deaths. $N$ Eng J Med 2010, 363:1981-5.

7. Oderda GM, Said Q, Eveans R, Stoddard G, Lloyd J, Jackson R, Rublee D, Samore MH: Opioid-related adverse events in surgical hospitalizations: Impact on cost and length of stay. Ann Pharmacother 2007, 4I:400-6.

\section{FlOOOPrime
RECOMMENDED}

8. Davies EC, Green CF, Taylor S, Willimason PR, Motram DR, Pirmohamed M: Adverse drug reactions in hospital in-patients: A prospective analysis of $\mathbf{3 6 9 5}$ patient episodes. PLoS One 2009, 4:e4439.

\section{FlOOOPrime}

\section{RECOMMENDED}

9. Oderda GM, Gan TJ, Johnson BH, Robinson SB: Effect of opioidrelated adverse events on outcomes in selected surgical patients. J Pain Palliat Care Pharmacother 2013, 27:62-70.

\section{FlOOOPrime}

\section{RECOMMENDED}

10. Pattinson KTS: Opioids and the control of respiration. $\mathrm{Br} J$ Anaesth 2008, 100:747-58.

\section{FIOOOPrime} RECOMMENDED

II. Olofsen E, Boom M, Nieuwenhuijs D, Sarton E, Aarts L, Dahan A: Modeling the non-steady-state respiratory effects of remifentanil in awake and propofol sedated healthy volunteers. Anesthesiology 2010, 21 2:1382-95.

\section{FlOOOPrime \\ RECOMMENDED}

12. Brown KA, Laferrière A, Lakheeram I, Moss IR: Recurrent hypoxemia in children is associated with increased analgesic sensitivity to opiates. Anesthesiology 2006, I 05:665-9.

\section{FIOOOPrime \\ RECOMMENDED}

13. Moss I, Brown KA, Laferrière A: Recurrent hypoxia in rats during development increases subsequent respiratory sensitivity to fentanyl. Anesthesiology 2006, I05:715-8.

\section{FlOOOPrime \\ RECOMMENDED}

14. Niesters M, Mahajan RP, Aarts L, Dahan A: High-inspired oxygen concentration further impairs opioid-induced respiratory depression. Br J Anaesth 20 I3, I I 0:837-4I.

15. Mercadante S, Porzio G, Ferrera P, Aielli F, Adile C, Ficorella C, Giarratano A, Casuccio A: Tapentadol in cancer pain management: A prospective open-label study. Curr Med Opin 2012, 28: $1775-9$.

\section{FlOOOPrime}

\section{RECOMMENDED}

16. Golder FJ, Hewitt MW, McLeod JF: Respiratory stimulant drugs in the post-operative setting. Resp Physiol Neurobiol 2013, I 89:395-402

17. Olofsen E, van Dorp E, Aarts L, Smith TW, Dahan A, Sarton E: Naloxone reversal of morphine- and morphine-6-glucuronideindiced respiratory depression in healthy volunteers: A mechanism-based pharmacokinetic-pharmacodynamic modeling study. Anesthesiology 2010, I I 2:1417-27.

\section{FlOOOPrime
RECOMMENDED}

18. Cotten JF, Keshavaprasad B, Laster MJ, Eger El, Yost CS: The ventilatory stimulant doxapram inhibits TASK tandem pore $\left(K_{2 P}\right)$ potassium channel function but does not affect minimum alveolar concentration. Anesth Analg 2006, 102:779-85.
19. Cotten JF: TASK-I (KCNK3) and TASK-3 (KCNK9) tandem pore potassium channel antagonists stimulate breathing in isoflurane-anesthetized rats. Anesth Analg 20I3, I l 6:810-6.

\section{FlOOPrime}

\section{RECOMMENDED}

20. Bamagbade OA: Advantages of doxapram for post-ananesthesia recovery and outcomes in bariatric surgery patients with obstructive sleep apnea. Eur J Anaesthesiol 20 I I, 28:387-8.

\section{FlOOOPrime
RECOMMENDED}

21. Roozekrans M, van der Schrier R, Hoskins P, McLeod J, Dahan A: Doxapram reduces alfentanil plasma concentrations associated with an increase in cardiac output [abstract]. Anesthesiology 2013, I 19:A3165.

22. McCartney CE, McClafferty H, Huibant JM, Rowan EG, Shipston MJ, Rowe IC: A cysteine-rich motif confers hypoxia sensitivity to mammalian large conductance voltage and $\mathbf{C a}$-activated $\mathrm{K}$ (BK) channel alpha-subunits. Proc Natl Acad Sci 2005, I02: $17870-6$

\section{FlOOOPrime \\ RECOMMENDED}

23. McLeod JF, Leempoels JM, Peng SX, Dax SL, Myers L, Golder F]: GAL-02I, a new intravenous $\mathrm{BK}_{\mathrm{Ca}}$-channel blocker, is well tolerated and stimulates ventilation in healthy volunteers. $\mathrm{Br}$ J Anaesth 2014, [Epub ahead of print].

24. Roozekrans $M$, van der Schrier R, van Gerven J, Okkerse P, Peng S, Hoskins P, McLeod JF, Dahan A: GAL-02I, a new intravenous selective potassium-channel blocker, reverses opioid-induced respiratory depression with no impairment of opioid analgesia [abstract]. Presented at $3^{\text {rd }}$ Annual Meeting of the Society of Anesthesia and Sleep Medicine: I0-I I October, 20I3; San Francisco, CA.

25. Roozekrans $M$, van der Schrier R, Okkerse P, Hay J, McLeod J, Dahan A: Two studies on reversal of opioid-induced respiratory depression by BK-channel blocker GAL02 I in human volunteers. Anesthesiology 2014, [Epub ahead of print].

26. Manzke T, Niebert M, Koch UR, Caley A, Vogelgesang S, Hülsmann S, Ponimaskin E, Müller U, Smart TG, Harvey RJ, Richter DW: Serotonin receptor IA-modulated phosphorylation of glycine receptor $\alpha 3$ controls breathing in mice. J Clin Invest 2010, I 20:4 I I8-28.

\section{FlOOOPrime
RECOMMENDED}

27. Montandon G, Qin W, Liu H, Ren J, Greer JJ, Horner RL: PreBötzinger complex neurokinin-I receptor-expressing neurons mediate opioid-induced respiratory depression. J Neurosci 2011, 31:1291-301.

\section{FlOOOPrime} RECOMMENDED

28. Mitchell GS: Back to the future: Carbon dioxide chemoreceptors in the mammalian brain. Nat Neurosci 2004, 7:1288-90.

29. Ren J, Poon BY, Tang Y, Funk GD, Greer JJ: Ampakines alleviate respiratory depression in rats. Am J Resp Crit Care Med 2006. | 74: |384-9|.

\section{FlOOOPrime}

\section{RECOMMENDED}

30. Ren J, Ding X, Funk GD, Greer JJ: Ampakine CX7I7 protects against fentanyl-induced respiratory depression and lethal apnea in rats. Anesthesiology 2009, I | 0:1364-70.

\section{FlOOOPrime
RECOMMENDED}

31. Oertel BG, Felden L, Tran PV, Bradshaw MH, Angst MS, Schmidt H, Johnson G, Greer J], Geisslinger G, Varney MA, Lötsch J: Selective antagonism of opioid-induced ventilatory depression by an 
ampakine molecule in humans without loss of opioid analgesia. Clin Pharmacol Ther 2010, 87:204-II.

\section{FlOOOPrime}

32. Ren J, Lenal F, Yang M, Ding X, Greer J]: Coadministration of the ampakine CX717 with propofol reduces respiratory depression and fatal apneas. Anesthesiology 2013, I I 8:1437-5.

\section{FlOOOPrime \\ RECOMMENDED}

33. Manzke T, Guenther U, Ponimaskin EG, Haller M, Deutschmann M, Schwarzacher S, Richter DW: 5HTA4(a) receptors avert opioidinduced breathing depression without loss of analgesia. Science 2003, 30I:226-9.

\section{FloOOPrime}

\section{RECOMMENDED}

34. Oertel BG, Schneider A, Rohrbacher M, Schmidt H, Tegeder I, Geisslinger G, Lötsch J: the partial 5-hydroxytriptamine IA receptor agonist buspirone does not antagonize morphineinduced respiratory depression in humans. Clin Pharmacol Ther 2007, 8I:59-68.

FlOOOPrime RECOMMENDED

35. Lötsch J, Skarke C, Schneider A, Hummel T, Geisslinger G: The 5-hydroxytriptamine 4 receptor agonist mosapride does antagonize morphine-induced respiratory depression. Clin Pharmacol Ther 2005, 78:278-87.

\section{FIOOOPRime}

36. Dahan A, Roozekrans $M$, van der Schrier R, Smith $T$, Aarts $L$ : Primum non nocere or How to resolve drug-induced respiratory depression. Anesthesiology 2013, I | 8: 1261-3.

37. Niesters M, Overdyk F, Smith T, Aarts L, Dahan A: Opioid-induced respiratory depression in paediatrics: $A$ review of case reports. Br J Anaesth 2013, I I 0:175-82.

38. Dahan A, Overdyk F, Smith T, Aarts L, Niesters M: Pharmacovigilance: a review of opioid-induced respiratory depression in chronic pain patients. Pain Physician 2013, 16:E85-94.

39. Overdyk F, Dahan A, Roozekrans M, van der Schrier R, Aarts L, Niesters M: Opioid-induced respiratory depression (OIRD) in the acute care setting; A Compendium of Case Reports. Pain Manag 2014, [Epub ahead of print].

40. Taft A, Ronen M, Epps C, Waugh J, Wales R: A novel Integrated Pulmonary Index (IPI) quantifies heart rate, $\mathrm{ETCO}_{2}$, respiratory rate and $\mathrm{SpO}_{2}$ [abstract]. Anesthesiology 2008, I09:AI682.

4I. Shaoul R: The value of Integrated Pulmonary Index (IPI) monitoring during endoscopies in children [abstract]. Anesth Analg 2011, I I3:S20.

42. Curry JP, Lynn LA: Threshold monitoring, alarm fatigue, and the patterns of unexpected hospital death. APSF Newsletter 20II, 26:32. 